\title{
Stability of recent and remote contextual fear memory
}

\author{
Paul W. Frankland, ${ }^{1,2,3,6}$ Hoi-Ki Ding, ${ }^{1,2}$ Eiki Takahashi, ${ }^{3,4}$ Akinobu Suzuki, ${ }^{5}$ \\ Satoshi Kida, ${ }^{5}$ and Alcino J. Silva ${ }^{3}$ \\ ${ }^{1}$ Program in Neuroscience and Mental Health, Hospital for Sick Children, Toronto, Ontario, Canada M5G 1 X8; ${ }^{2}$ Department of \\ Physiology, University of Toronto, Ontario, Canada M5S 1A8; ${ }^{3}$ Departments of Neurobiology, Psychiatry and Psychology and \\ Brain Research Institute, University of California-Los Angeles, California 90095-1761, USA; ${ }^{4}$ Tsukuba Research Laboratory, Eisai \\ Co. Ltd., Tsukuba, Ibaraki 300-2635, Japan; ${ }^{5}$ Departments of Agricultural Chemistry and Bioscience, Faculty of Applied Science, \\ Tokyo University of Agriculture, Tokyo 156-8502, Japan
}

\begin{abstract}
Following initial encoding, memories undergo a prolonged period of reorganization. While such reorganization may occur in many different memory systems, its purpose is not clear. Previously, we have shown that recall of recent contextual fear memories engages the dorsal hippocampus (dHPC). In contrast, recall of remote contextual fear memories engages a number of different cortical regions, including the anterior cingulate cortex (ACC). To examine whether this reorganization leads to greater memory stability, we examined reconsolidation of $1 \mathrm{~d}$-old (recent) and $36 \mathrm{~d}$-old (remote) contextual fear memory in mice. We infused the protein synthesis inhibitor, anisomycin (ANI), into either the $\mathrm{AHPC}$ or ACC immediately following retrieval of either a recent or remote contextual fear memory. In the dHPC, ANI infusions disrupted subsequent expression of recent, but not remote, contextual fear memory. Similar infusions into the ACC had no effect on either recent or remote contextual fear memories, whereas systemically applied ANI blocked subsequent remote memory expression when long re-exposure durations were used. Together, these data suggest that as memories mature they become increasingly stable. Furthermore, the dissociation between the effects of systemically and centrally administered ANI on remote memory suggests that stability is due, in part, to the distributed nature of remote contextual fear memories.
\end{abstract}

Memories are not formed instantaneously. Instead, following initial encoding, memories appear to undergo a prolonged period of reorganization (McClelland et al. 1995; Squire and Alvarez 1995; Dudai 2004; Wiltgen et al. 2004; Frankland and Bontempi 2005). The result of this reorganization is that circuits underlying encoding or initial storage may differ from those required for permanent storage. This type of reorganization has most often been studied in cortico-hippocampal circuits (Squire et al. 2004; Frankland and Bontempi 2005). However, time-dependent reorganization is observed across many different memory systems (Shadmehr and Holcomb 1997; Tronel and Sara 2002; Bahar et al. 2004) and in many different species, including invertebrates (McBride et al. 1999; Menzel 2001; Keller et al. 2005). While these studies indicate that reorganization might be a somewhat ubiquitous process during memory maturation, its exact purpose is still not clear. Because behavioral expression of memory doesn't necessarily change over time, one possibility is that reorganization leads to greater memory stability (Dudai and Eisenberg 2004; Alberini 2005; Stickgold and Walker 2005).

One way to probe memory stability is to apply consolidation blockers (e.g., protein synthesis inhibitors) during or immediately following memory retrieval. Such manipulations interfere with the restabilization (or reconsolidation) of memories, leading to amnesia (Nader 2003). While reconsolidation has now been demonstrated across species and memory paradigms (Nader 2003; Dudai and Eisenberg 2004), post-reactivation protein synthesis blockade does not always lead to amnesia (Vianna et al. 2001; Kraus et al. 2002; Biedenkapp and Rudy 2004; Cammarota

\footnotetext{
${ }^{6}$ Corresponding author.
}

E-mail paul.frankland@sickkids.ca; fax (416) 813-6846.

Article is online at http://www.learnmem.org/cgi/doi/10.1101//m.183406. et al. 2004; Pedreira et al. 2004). One important variable appears to be the age of the memory. Recent studies in rodents (Milekic and Alberini 2002; Suzuki et al. 2004), as well as medaka fish (Eisenberg and Dudai 2004), have shown that as memories mature they become increasingly immune to disruption by proteinsynthesis blockers. This suggests that there might be a trade-off between plasticity and stability as memories age.

This age-stability relationship has so far only been investigated using systemically applied consolidation blockers (Milekic and Alberini 2002; Eisenberg and Dudai 2004; Suzuki et al. 2004). However, we have recently mapped brain regions involved in the recall of recent and remote contextual fear memories in mice (Frankland et al. 2004). These studies showed that the dHPC was strongly activated only following recall of the recent (day-old) fear memory. In contrast, a number of different cortical regions (including the ACC) were strongly activated only following recall of the remote (month-old) fear memory. Here we target these regions to probe the stability of recent and remote contextual fear memories. Using identical apparatus and procedures as in our mapping studies (Frankland et al. 2004), we examined the effects of post-reactivation blockade of protein synthesis on subsequent expression of recent and remote contextual fear memory.

\section{Results}

ANI disrupts Fos induction following PTZ treatment We first evaluated whether our ANI manipulations disrupted protein synthesis. To do this we examined whether ANI attenuates induction of the activity-regulated gene, $c$-fos, produced by the chemical convulsant pentylenetetrazol (PTZ). In the first study, 
A

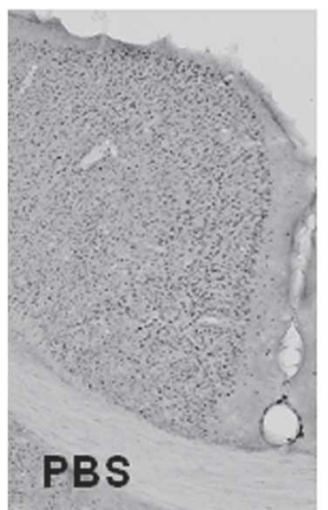

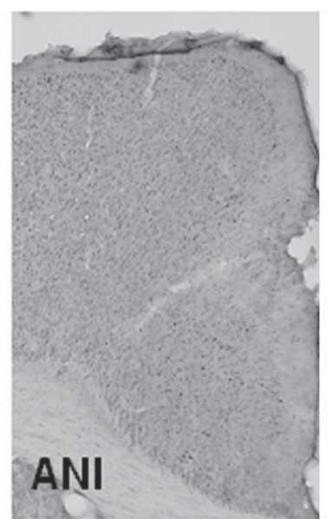

B

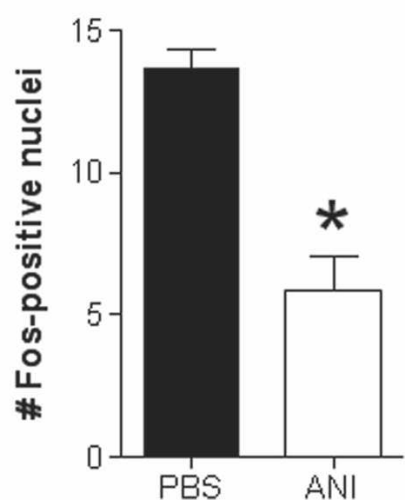

Figure 1. ANI infusions into the ACC attenuate Fos expression induced by systemic injections of PTZ. (A) Representative photomicrographs of ACC in mice receiving either PBS or ANI infusions into the ACC. PTZ induction of Fos is reduced by pretreatment with ANI. (B) Quantification of Fos expression in mice pretreated with PBS and ANI ( ${ }^{\star} P<0.05$; see text for details). Number of Fos-positive nuclei per $100 \times 100-\mu \mathrm{m}$ field are shown.

mice received intra-ACC infusions of PBS or ANI. Thirty minutes following this pretreatment, mice received PTZ (50 mg/kg, ip). This dose of PTZ produced clonic convulsions (i.e., sudden twitching of head or jerky movement of body) in the majority of mice, and strong Fos expression throughout the brain (including the ACC). Importantly, Fos expression in the ACC was reduced by over $50 \%$ in mice pretreated with ANI, consistent with the idea that ANI attenuates protein synthesis $\left(t_{(13)}=5.94, P<0.05\right)$ (Fig. 1). This reduction in Fos expression was evident in a roughly circular region $1.0-1.5 \mathrm{~mm}$ in diameter, below the tip of the injector. This indicates that infusions were largely restricted to the ACC, with limited diffusion to neighboring structures.

In the second study, mice were pretreated with systemic injections of PBS or ANI. Again, PTZ treatment induced strong Fos expression and this expression was reduced by ANI pretreatment in the ACC (PBS: $13.94 \pm 0.89$; ANI: $6.21 \pm 0.89$ $\left.\left[t_{(8)}=6.21, P<0.05\right]\right)$, as well as other cortical regions, including the retrosplenial (PBS: $9.14 \pm 1.08$; ANI: $0.50 \pm 0.14$ $\left.\left[t_{(12)}=7.95, P<0.05\right]\right)$ and perirhinal (PBS: $5.04 \pm 1.12$; ANI: $\left.1.16 \pm 0.27\left[t_{(12)}=3.38, P<0.05\right]\right)$ cortex (Fig. 2). Together these studies establish that the ANI manipulations used in the behavioral studies disrupt protein synthesis, measured here as a reduction in Fos expression induced by the chemical convulsant, PTZ.

\section{Post-reactivation blockade of protein synthesis in the dHPC disrupts subsequent expression of recent, but not remote, contextual fear memory}

In this first series of behavioral experiments, mice were trained with three footshocks. Then, either 1-d (recent) or 36-d (remote) later mice were placed back into the context for $2.5 \mathrm{~min}$ (reexposure). Immediately following this context re-exposure, mice received infusions of ANI into the AHPC. One day following this, they were tested.

We found that the destabilizing effects of blocking protein synthesis in the dHPC following memory recall depended on the age of the memory (Fig. 3). All groups of mice exhibited similar levels of freezing when re-exposed to the conditioning context (Recent: $F_{(1,14)}=0.06, P>0.05$; Remote: $F_{(1,18)}=0.16, P>0.05$ ). However, intra-dHPC infusions of ANI following the retrieval of a 1-d-old (recent) contextual fear memory blocked expression of that memory tested one day later $\left(F_{(1,14)}=11.34, P<0.05\right)$ (Fig. $3 \mathrm{~A})$. In contrast, similar infusions following the retrieval of 36d-old (remote) contextual fear memory had no effect on subsequent memory expression $\left(F_{(1,18)}=0.44, P>0.05\right)$ (Fig. 3B).

These data indicate that infusions of ANI into the dHPC disrupt reconsolidation of recent, but not remote, contextual fear memories (delay $\times$ drug interaction: $F_{(1,32)}=4.99, P<0.05$ ) (Fig. 3C). This effect on recent memory was contingent on memory reactivation. When the reactivation was omitted, similar ANI infusions had no effect on subsequent expression of that memory tested $1 \mathrm{~d}$ later $\left(F_{(1,15)}=0.69, P>0.05\right)$ (Fig. 3D).

To explore the generality of this effect on recent contextual fear memories, we also trained another set of mice with a single footshock and re-exposed them to the conditioning chamber 1-d later. As before, we found that ANI infusions disrupted reconsolidation of a recent contextual fear memory $\left(F_{(1,11)}=5.76\right.$, $P<0.05)$ (Fig. 3E), demonstrating that ANI blocks reconsolidation of recent contextual fear memories regardless of whether mice are weakly or strongly fear conditioned. Histological analyses revealed that
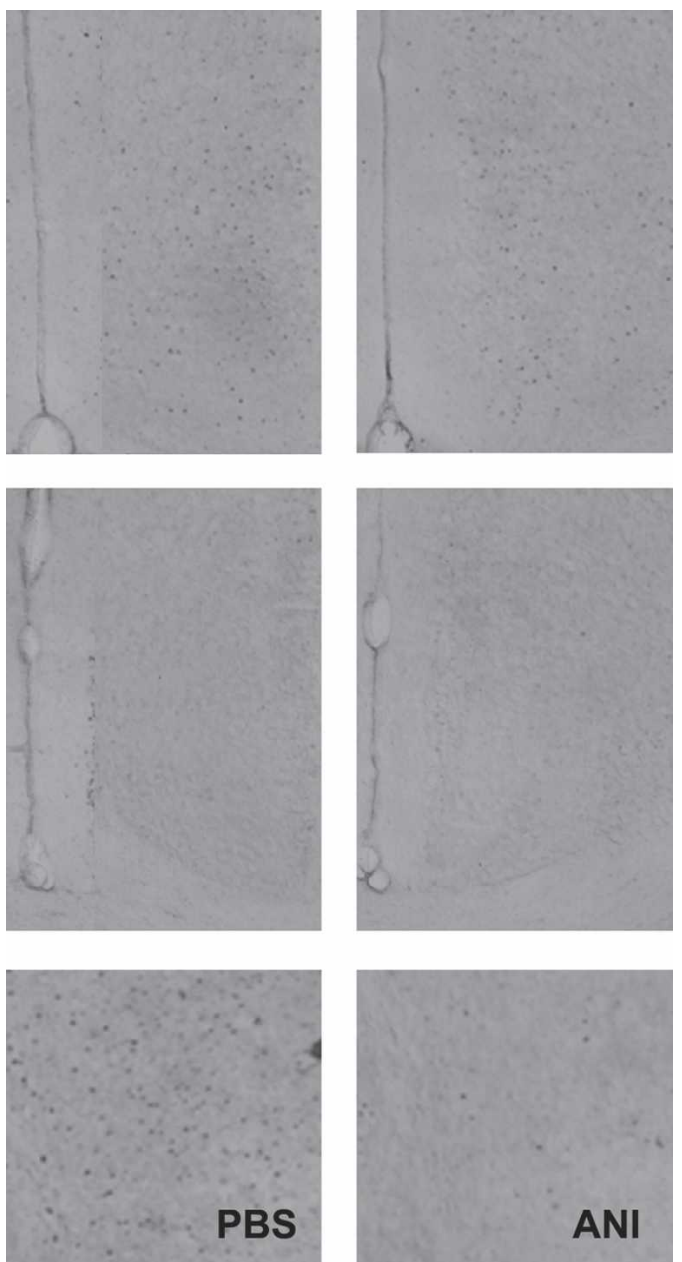

Figure 2. Systemic ANI injections attenuate cortex-wide Fos expression induced by systemic injections of PTZ. Representative photomicrographs of ACC (top), retrosplenial cortex (middle), and perirhinal cortex (bottom) in mice pretreated with either PBS or ANI. In each of these cortical regions, Fos expression is reduced in mice pretreated with ANI. 
A

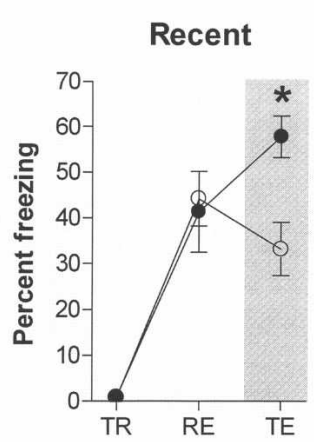

D

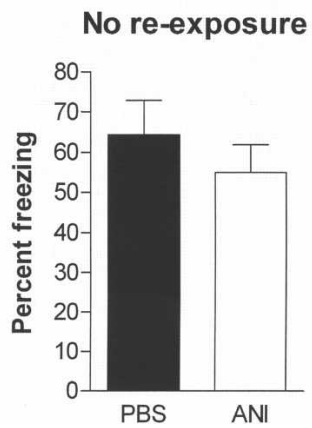

B

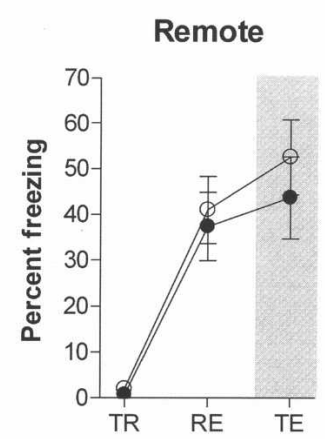

E

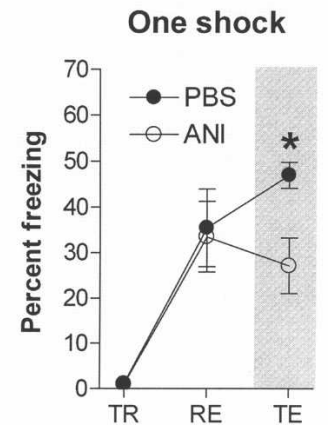

C

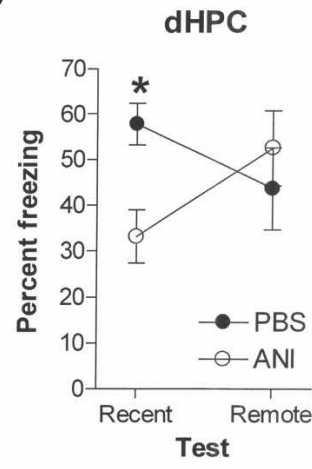

hippocampus, intra-ACC infusions of ANI following the retrieval of either recent $\left(F_{(1,15)}=0.51, P>0.05\right)$ or remote $\left(F_{(1,18)}=0.14, P>0.05\right)$ contextual fear memory had no effect on subsequent memory expression (Fig. 4A,B). This result is confirmed by the absence of a significant delay $\times$ drug interaction $\left(F_{(1,33)}=0.36, P>0.05\right)$ (Fig. 4C). Therefore, whereas inactivation of the ACC blocks retrieval of 36-d-old (remote) contextual fear memories (Frankland et al. 2004), blocking protein synthesis following retrieval does not affect subsequent stability of that memory. Histological analyses revealed that the tips of the guide cannulae were correctly located just dorsal to the ACC in these and all following experiments.

\section{Intra-ACC blockade of protein synthesis fails to disrupt reconsolidation of remote contextual fear memory following extended context re-exposure}

The duration of re-exposure is an important variable in reconsolidation experiments. Previous studies have established that longer duration re-exposures tend to have greater destabilizing effects on memory than shorter ones (Pedreira and Maldonado 2003; Suzuki et al. 2004). We therefore tested whether intra-ACC infusions of ANI block reconsolidation when longer re-exposure durations were used lowing context re-exposure disrupted subsequent expression of recent $(A)$, but not remote $(B)$, contextual fear memory. The percent time spent freezing is shown during the training (TR), re-exposure (RE), and test phases (TE) of the experiment. A summary of the test freezing scores for these mice is shown in C. The destabilizing effects of intra-dHPC ANI on recent contextual fear memory are contingent on memory reactivation. When context re-exposure was omitted, ANI infusions into the dHPC had no effect on subsequent memory expression $(D)$. Intra-dHPC infusions of ANI also block reconsolidation of a weaker contextual fear memory. In this experiment, mice were trained with one, rather than three shocks $(E)$. Significant differences are marked by an asterisk $\left({ }^{*} P<0.05\right.$, see text for details).

the tips of the guide cannulae were correctly located just dorsal to the dHPC in these experiments.

Post-reactivation blockade of protein synthesis in the ACC has no effect on subsequent expression of recent or remote contextual fear memory We previously found that the ACC is activated following recall of remote contextual fear memory. Further experiments showing that (1) this activity is absent in $\alpha$-CaMKII ${ }^{+-}$mice that are unable to form remote memories, and (2) localized inactivation of this region specifically blocks remote memory, suggested that the ACC plays a crucial role in remote memory recall (Frankland et al. 2004). Therefore, we next examined the impact of blocking protein synthesis in the ACC on the stability of both recent and remote contextual fear memories (Fig. 4). Again, mice were trained with three footshocks, and 1 or $36 \mathrm{~d}$ later placed back in the conditioning context for $2.5 \mathrm{~min}$. During this re-exposure phase, all groups of mice exhibited similar levels of freezing (Recent: $F_{(1,15)}=0.11, P>0.05$; Remote: $\left.F_{(1,18)}=0.23, P>0.05\right)$. In contrast to the

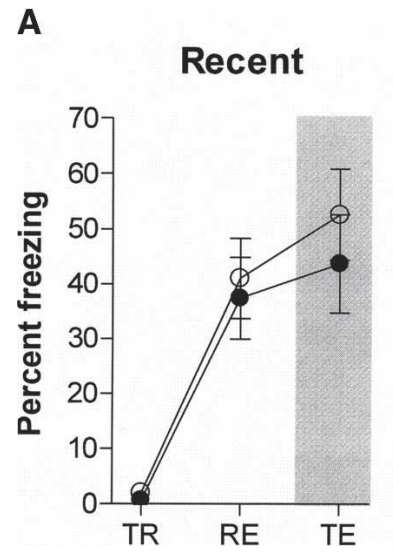

B

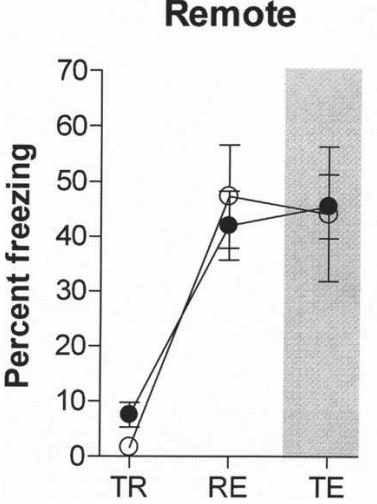

C

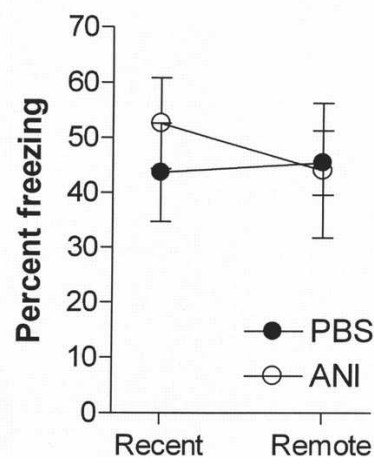

Figure 4. Post-reactivation blockade of protein synthesis in the ACC. Intra-ACC infusions of ANI following context re-exposure did not disrupt subsequent expression of recent $(A)$, or remote $(B)$, contextual fear memory. The percent time spent freezing is shown during the training (TR), reexposure (RE), and test phases (TE) of the experiment. A summary of the test freezing scores for these mice is shown in $C$. 
A
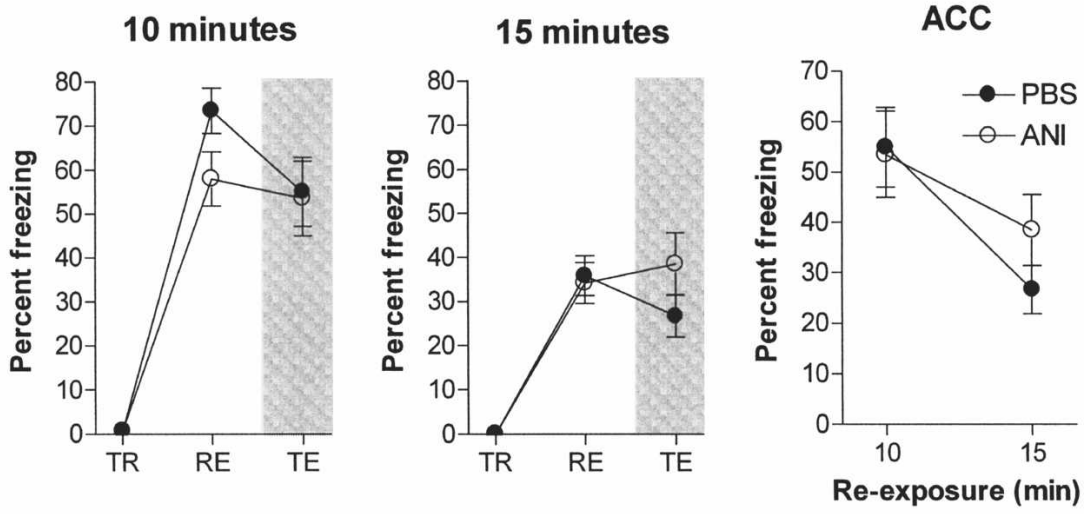

B

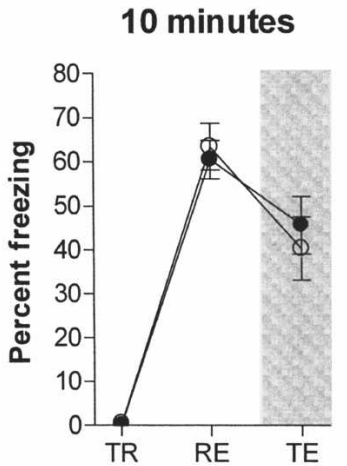

C
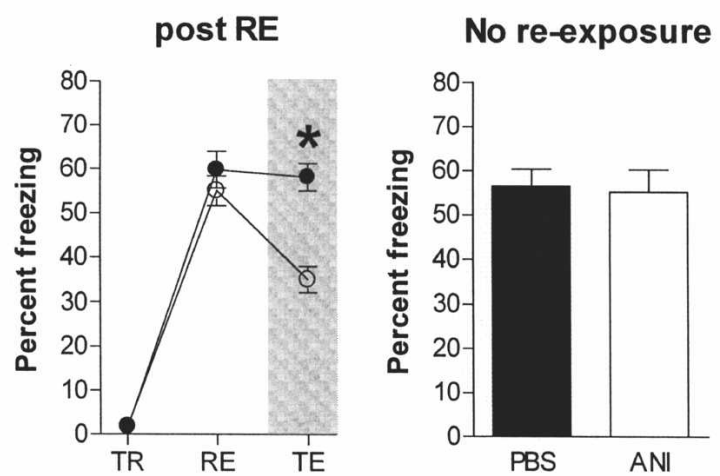

Figure 5. Effects of context re-exposure duration on reconsolidation of remote contextual fear memory. For each experiment, the percent time spent freezing is shown during the training (TR), re-exposure (RE), and test phases (TE) of the experiment. (A) Intra-ACC infusions of ANI had no effect on subsequent expression of remote contextual fear memory using either 10- or 15-min context re-exposures. These test data are summarized in the graph on the far right. (B) Systemic injections of ANI blocked reconsolidation of remote contextual fear memory only when the longer (15-min) context re-exposure was used. These test data are summarized in the graph on the far right. (C) Systemic injection of $\mathrm{ANI}$ immediately following (rather than preceding) a 15-min re-exposure also blocks reconsolidation (left). The destabilizing effects of ANI on remote contextual fear memory are contingent on memory reactivation. When context re-exposure was omitted, systemic ANI injections had no effect on subsequent memory expression (right). Significant differences are marked by an asterisk $\left({ }^{*} P<0.05\right.$, see text for details).

freezing levels were lower in mice re-exposed for $15 \mathrm{~min}$, suggesting that this longer duration re-exposure may start to produce some extinction. In either case, intra-ACC infusions of ANI following either the 10-min $\left(F_{(1,17)}=0.16, P>0.05\right)$ or 15 -min $\left(F_{(1,17)}=1.98, P>0.05\right)$ re-exposure had no effect on subsequent contextual fear memory expression tested 1-d later. These results indicate that post-reactivation infusions of ANI into the ACC fail to disrupt subsequent expression of remote contextual fear memories, even when longer duration re-exposures are used.

Systemic ANI injections disrupt reconsolidation of remote contextual fear memories following extended duration context re-exposures

One reason why reactivated remote contextual memories may be insensitive to the amnesic effects of ANI is because they are supported by distributed cortical networks (McClelland et al. 1995; Frankland and Bontempi 2005). It is possible that a more global, cortex-wide disruption of protein synthesis would block the reconsolidation of remote contextual fear memories. To test this, we examined the effects of systemically administered ANI on remote contextual fear memory. In the first series of experiments (Fig. 5B), mice were trained as above and $36 \mathrm{~d}$ later re-exposed to the conditioning context for either 10 or 15 $\mathrm{min}$. Prior to this re-exposure, mice received injections of ANI $(150 \mathrm{mg} / \mathrm{kg}$, i.p.) or PBS. Both ANI- and PBS-treated mice exhibited similar levels of freezing when re-exposed to the conditioning context $\left(10 \mathrm{~min}: F_{(1,18)}=0.18, P>0.05\right.$; 15 min: $\left.F_{(1,18)}=0.04, P>0.05\right)$. However, only ANI injections prior to the 15min re-exposure disrupted subsequent memory tested $1 \mathrm{~d}$ later $\left(F_{(1,18)}=6.16\right.$, $P<0.05)$. Similar infusions prior to the 10 min re-exposure had no effect on subsequent memory expression $\left(F_{(1,18)}=0.30, P>0.05\right)$.

In the previous central injection experiments, ANI was infused after, rather than before context re-exposure. Therefore, we ran an additional experiment where mice received systemic injections of ANI or PBS immediately after a 15min re-exposure. Mice in the ANI and PBS groups exhibited similar levels of freezing during the re-exposure phase $\left(F_{(1,18)}=1.42, P>0.05\right)$. However, consistent with our earlier results, systemic ANI treatment disrupted subsequent memory tested $1 \mathrm{~d}$ later $\left(F_{(1,18)}=29.73\right.$, $P<0.05)$ (Fig. 5C). Finally, we tested whether this effect was contingent on memory reactivation. When this reactivation was omitted, similar ANI injections had no effect on subsequent expression of that memory tested $1 \mathrm{~d}$ later $\left(F_{(1,15)}=0.05, P>0.05\right)$ (Fig. 5C).

These data indicate that systemic ANI injections disrupt reconsolidation of remote contextual fear memories, but only when longer duration re-exposures are used. The effects of systemically administered ANI contrast with those of intra-ACC infused ANI. Under identical conditions, local blockade of protein 
synthesis in the ACC had no effect on subsequent memory expression, suggesting that a more global disruption of protein synthesis is necessary to destabilize remote memory. This is different from the situation for recent contextual fear memories. Both local (dHPC) (present study; Suzuki et al. 2004) or systemic (Suzuki et al. 2004) blockade of protein synthesis disrupts reconsolidation of recent contextual fear memories.

\section{Discussion}

We used a contextual fear-conditioning paradigm in mice to examine how time-dependent reorganization might affect memory stability. Two features of contextual fear conditioning make it especially suited for this analysis. First, contextual fear conditioning has been used extensively to study behavioral and molecular determinants of reconsolidation in mice (Kida et al. 2002; Biedenkapp and Rudy 2004; Fischer et al. 2004; Lattal and Abel 2004; Suzuki et al. 2004; von Hertzen and Giese 2005), as well as other species (Debiec et al. 2002; Pedreira and Maldonado 2003; Biedenkapp and Rudy 2004; Lee et al. 2004; Pedreira et al. 2004; Merlo et al. 2005). Second, imaging and lesion experiments indicate that the circuits supporting contextual fear undergo significant reorganization in the month following learning (Anagnostaras et al. 1999; Shimizu et al. 2000; Frankland et al. 2001, 2004). The current experiments indicate that blocking protein synthesis in the dHPC disrupts recent, but not remote contextual fear memories. Similar infusions into the ACC had no effect on either recent or remote contextual fear memories, whereas systemically applied ANI blocked subsequent remote memory expression when long re-exposure durations were used. Together, these data suggest that as memories mature they become increasingly stable. Furthermore, the dissociation between the effects of systemically and centrally administered ANI on remote memory suggests that stability is due, in part, to the distributed nature of remote contextual fear memories.

The effects of intra-dHPC infusions of ANI on the stability of recent and remote contextual fear memory parallels the timedependent role the hippocampus plays in the storage of these types of memories. Using identical apparatus, behavioral procedures, and retention delays, we previously showed that the hippocampus was activated following recall of recent, but not remote contextual fear memory (Frankland et al. 2004). Here we found that blocking protein synthesis in the dHPC-disrupted reconsolidation of recent contextual fear memories, regardless of whether mice had been trained using a weak (one-shock) or strong (three-shock) protocol. However, we found that similar infusions had no effect on remote contextual fear memories, consistent with the lack of involvement of the dHPC in processing contextual fear memories at later time points (Hall et al. 2001; Frankland et al. 2004; von Hertzen and Giese 2005). This was still the case even when a longer re-exposure (10-min) was used (data not shown). This lack of effect on remote contextual fear memory contrasts with a previous study in rats (Debiec et al. 2002). In this study, intrahippocampal infusions of ANI blocked reconsolidation of both recent (1-d-old) and remote (i.e., 45-dold) contextual fear memories. This discrepancy may reflect species differences between rats and mice. Alternatively, it is possible that infusion of a larger volume or dose would be more effective in destabilizing remote memory in our study. However, our data clearly demonstrate a time-dependent stability gradient, with recent memories more sensitive to intra-dHPC infusions of ANI compared with remote memories.

We previously found that the ACC was activated following recall of remote (but not recent) contextual fear memories, and that inactivation of the ACC specifically disrupts recall of these memories (Frankland et al. 2004). Here we found that post- retrieval blockade of protein synthesis in the ACC does not destabilize remote contextual fear memories. This lack of effect on remote memories suggests two possibilities. First, the ACC may only be necessary for retrieval (and not storage) of remote contextual fear memories. Such a situation would suggest a division of labor in the cortex with the ACC coordinating retrieval of memories that are stored in more posterior cortical regions (Frankland and Bontempi 2005). If this were the case, then postreactivation disruption of protein synthesis in more posterior cortical regions might disrupt the reconsolidation of remote contextual fear memories.

A second possibility is that the distributed nature of remote memory protects against the destabilizing effects of locally applied protein synthesis inhibitors. Using cellular imaging approaches, we have previously shown that recall of remote contextual fear memory is associated with activation of multiple cortical regions (Frankland et al. 2004), suggesting that remote contextual fear memories are supported by a broadly distributed network. In the present series of experiments, we found that only systemically applied ANI disrupted subsequent expression of remote contextual fear memory, albeit only when a longer duration context re-exposure was used. Therefore, whereas local blockade of protein synthesis in the dHPC was sufficient to destabilize a recent contextual fear memory, a more global disruption of protein synthesis appears to be necessary to destabilize remote contextual fear memory.

Together, these experiments have started to explore the relationship between memory age and memory stability. Consistent with previous reports (Milekic and Alberini 2002; Pedreira and Maldonado 2003; Suzuki et al. 2004), our data indicate that as memories mature they become increasingly immune to the destabilizing effects of protein-synthesis blockers. Gradual reorganization of contextual fear memories in distributed cortical (or cortico-hippocampal) networks (McClelland et al. 1995; Nadel and Moscovitch 1997; Squire et al. 2004; Wiltgen et al. 2004; Frankland and Bontempi 2005) may underlie this increased stability.

\section{Materials and Methods}

\section{Animals}

Male C57Bl/6 mice were used in these experiments. For the local infusion experiments, these mice were purchased from Taconic Farms. For the systemic injection experiments, they were purchased from Charles River. Mice were maintained on a 12-h light/12-h dark cycle, and had free access to food and water. Mice were at least $8 \mathrm{wk}$ of age at the start of experiments, and all behavioral procedures were conducted during the light phase of the cycle. Experiments were conducted blind to the treatment condition of the mouse.

\section{Surgery}

Under chloral hydrate anesthesia and using standard stereotaxic procedures, stainless-steel guide cannulae (22-gauge) were implanted into the dHPC $(-2.0 \mathrm{~mm}, \pm 2.0 \mathrm{~mm},-2.0 \mathrm{~mm})$ or ACC $(+0.8 \mathrm{~mm}, 0 \mathrm{~mm},-1.0 \mathrm{~mm})$. Mice were allowed to recover for at least $1 \mathrm{wk}$ following surgery. Following this, they were handled for three consecutive days prior to the commencement of contextual fear conditioning.

\section{Drugs and infusion procedures}

The protein synthesis inhibitor, Anisomycin (ANI; Sigma), was used in these experiments. For the local infusion studies, ANI $(100 \mu \mathrm{g} / \mu \mathrm{L})$ was dissolved in phosphate-buffered saline (PBS) and the $\mathrm{pH}$-adusted to 7.0-7.4. ANI was infused immediately following the re-exposure phase of the experiment. Mice were briefly anesthetized with halothane to facilitate insertion of the injec- 
tion cannula. Infusions into the $\mathrm{dHPC}(0.75 \mu \mathrm{L})$ or ACC $(0.50 \mu \mathrm{L})$ were made at a rate of $0.2 \mu \mathrm{L} / \mathrm{min}$. The injection cannula (26gauge) was left in place for $2 \mathrm{~min}$ following the infusion. This dose of locally infused ANI inhibits $>90 \%$ of protein synthesis for at least $4 \mathrm{~h}$ (Rosenblum et al. 1993). For the systemic injection experiments, ANI (150 mg/kg, i.p.) was injected $30 \mathrm{~min}$ prior to the re-exposure phase of the experiment. At this dose, ANI inhibits $>90 \%$ of protein synthesis in the brain in the first $2 \mathrm{~h}$ following injection (Flood et al. 1973).

\section{Effect of ANI manipulations on c-fos expression}

To indirectly examine the impact of ANI on protein synthesis inhibition, separate groups of mice received infusions of either PBS $(n=8)$ or ANI $(n=7)$ into the ACC, as described above. Thirty minutes following this, mice were administered the chemical convulsant pentylenetetrazol (PTZ; $50 \mathrm{mg} / \mathrm{kg}$, ip), and then $30 \mathrm{~min}$ later perfused transcardially. Brains were subsequently prepared for immunocytochemistry using anti-Fos primary rabbit polyclonal antibody $(1: 20000)$, as previously described (Frankland et al. 2004). Staining was revealed using the avidin-biotin peroxidase method (ABC kit). Quantitative analysis was performed using a NIH image-processing system and brain regions were anatomically defined according to the Paxinos and Franklin atlas (Paxinos and Franklin 2000). Immunoreactive neurons were counted by an experimenter unaware of the treatment condition.

In a second experiment, mice received systemic injections of either PBS or ANI, as described above. Thirty minutes later they were administered PTZ (50 mg/kg, ip), and then 30 min later perfused transcardially. Brains were subsequently prepared for Fos immunocytochemistry as above. The advantage of using PTZ in these experiments is that it induces high levels of Fos expression. This makes it easier to detect any reductions in Fos expression produced by pretreatment with ANI.

\section{Contextual fear-conditioning procedures}

The apparatus and general procedures for contextual fear conditioning have previously been described (Anagnostaras et al. 2000; Frankland et al. 2004; Suzuki et al. 2004). Mice were trained and tested in a conditioning chamber $(32 \mathrm{~cm} \times 25 \mathrm{~cm} \times 25 \mathrm{~cm})$, containing a stainless-steel shock-grid floor. For the systemic injection experiments, a similar, but smaller $(17.5 \mathrm{~cm} \times 17.5 \mathrm{~cm} \times$ $15 \mathrm{~cm}$ ), conditioning chamber was used.

Each experiment consisted of three phases: Training, reexposure, and testing. During each of these phases, freezing behavior (defined as a complete absence of movement, except for respiration) (Fanselow 1980) was measured using automated procedures (Anagnostaras et al. 2000).

In the first series of experiments, during training, mice were placed in the conditioning chamber for $5 \mathrm{~min}$. After $2 \mathrm{~min}$ they were presented with three unsignaled footshocks (2-sec duration, $0.75 \mathrm{~mA}, 1 \mathrm{~min}$ apart). During the re-exposure phase, mice were placed back into the conditioning context for 2.5 min either 1 or $36 \mathrm{~d}$ later. Immediately following this re-exposure, mice received infusions of PBS or ANI into the dHPC or ACC, respectively. One day later, contextual fear memory was assessed in a 2-min test. Mouse numbers were as follows: dHPC recent (PBS $n=9$; ANI $n=7$ ); dHPC remote (PBS $n=9$; ANI $n=11$ ); ACC recent (PBS $n=7$; ANI $n=10$ ); ACC remote (PBS $n=13$; ANI $n=7$ ).

In the second series of experiments, we first examined the effects of omitting the re-exposure. Accordingly, mice were trained as above with three footshocks. One day later they received infusions of PBS $(n=9)$ or ANI $(n=8)$ into the dHPC, but were not re-exposed to the conditioning chamber. The following day, contextual fear memory was assessed in a 2-min test. In a second experiment, we tested whether ANI disrupts reconsolidation of a weaker contextual fear memory. In this experiment, mice were trained with a single footshock (a $0.75 \mathrm{~mA}$ shock, delivered after 2 min of a 3-min training session) and re-exposed to the conditioning chamber for $2.5 \mathrm{~min}$ the following day. Immediately following this re-exposure, mice received infusions of either PBS $(n=5)$ or ANI $(n=8)$ into the dHPC. One day later, contextual fear memory was assessed in a 2-min test.

In the third series of experiments, we examined the effects of using longer duration context re-exposures on memory stability. Again, mice were trained with three footshocks. Thirty-six days later, they were re-exposed to the conditioning context for either 10 or $15 \mathrm{~min}$. For the local infusion experiments, mice received infusions of PBS (10 $\min , n=9 ; 15 \min , n=13$ ) or ANI (10 $\mathrm{min}, n=10 ; 15 \mathrm{~min}, n=6$ ) into the ACC immediately following this re-exposure. For the systemic injection experiments, mice received PBS (10 $\mathrm{min}, n=10 ; 15 \mathrm{~min}, n=10)$ or ANI (10 $\min , n=10 ; 15 \mathrm{~min}, n=10)$ injections $30 \mathrm{~min}$ before the reexposure. One day later, contextual memory was assessed in a 2-min test.

In addition, we also tested whether systemically administered ANI would have the same effects if injected immediately following the re-exposure. In this experiment, mice were trained as before with three footshocks. Then, $36 \mathrm{~d}$ later they were reexposed to the conditioning context for $15 \mathrm{~min}$. Immediately following this re-exposure mice received PBS $(n=10)$ or ANI $(n=10)$ injections and contextual fear memory was then assessed in a 2-min test the following day. In a separate group of mice, we examined the effects of omitting the re-exposure. Accordingly, mice were trained as above with three footshocks. Thirty-six days later they received systemic injections of PBS $(n=10)$ or ANI $(n=10)$, but were not re-exposed to the conditioning chamber. The following day, contextual fear memory was assessed in a 2-min test.

\section{Histology}

At the completion of the experiments, mice were overdosed with chloral hydrate and perfused transcardially with saline, followed by $4 \%$ formaldehyde solution to fix the brain tissue. Brains were removed, post-fixed in $4 \%$ formaldehyde solution, and cut into $50-\mu \mathrm{m}$ coronal sections on a cryostat. Sections were mounted on slides, stained with neutral red, and cannula placements were examined under a light microscope.

\section{Statistical analyses}

Separate ANOVAs were performed to determine the effects of ANI on freezing in the re-exposure and retention tests in each of the conditions (e.g., dHPC/recent, dHPC/remote, etc). In addition, two-way ANOVAs (drug [ANI, PBS] $\times$ delay [recent, remote]) were used to evaluate whether these treatments differentially affected recent vs. remote memory. $t$-tests were used to analyze the effects of ANI treatment on Fos expression.

\section{Acknowledgments}

This work was supported by grants from National Alliance for Research on Schizophrenia and Depression, the Canadian Institutes of Health Research (P.W.F.), the NIH (A.J.S.), and the Ministry of Education, Science and Culture, Japan (S.K.). We thank Rui Costa, Sheena Josselyn, and Nohjin Kee for comments on earlier drafts of this manuscript.

\section{References}

Alberini, C.M. 2005. Mechanisms of memory stabilization: Are consolidation and reconsolidation similar or distinct processes? Trends Neurosci. 28: 51-56.

Anagnostaras, S.G., Maren, S., and Fanselow, M.S. 1999. Temporally graded retrograde amnesia of contextual fear after hippocampal damage in rats: Within-subjects examination. J. Neurosci. 19: 1106-1114.

Anagnostaras, S.G., Josselyn, S.A., Frankland, P.W., and Silva, A.J. 2000. Computer-assisted behavioral assessment of Pavlovian fear conditioning in mice. Learn. Mem. 7: 58-72.

Bahar, A., Dorfman, N., and Dudai, Y. 2004. Amygdalar circuits required for either consolidation or extinction of taste aversion memory are not required for reconsolidation. Eur. J. Neurosci. 19: 1115-1118.

Biedenkapp, J.C. and Rudy, J.W. 2004. Context memories and reactivation: Constraints on the reconsolidation hypothesis. Behav. Neurosci. 118: 956-964.

Cammarota, M., Bevilaqua, L.R., Medina, J.H., and Izquierdo, I. 2004. Retrieval does not induce reconsolidation of inhibitory avoidance 
memory. Learn. Mem. 11: 572-578.

Debiec, J., LeDoux, J.E., and Nader, K. 2002. Cellular and systems reconsolidation in the hippocampus. Neuron 36: 527-538.

Dudai, Y. 2004. The neurobiology of consolidations, or, how stable is the engram? Annu. Rev. Psychol. 55: 51-86.

Dudai, Y. and Eisenberg, M. 2004. Rites of passage of the engram: Reconsolidation and the lingering consolidation hypothesis. Neuron 44: 93-100.

Eisenberg, M. and Dudai, Y. 2004. Reconsolidation of fresh, remote, and extinguished fear memory in Medaka: Old fears don't die. Eur. J. Neurosci. 20: 3397-3403.

Fanselow, M.S. 1980. Conditional and unconditional components of post-shock freezing. Pavlov. J. Biol. Sci. 15: 177-182.

Fischer, A., Sananbenesi, F., Schrick, C., Spiess, J., and Radulovic, J. 2004. Distinct roles of hippocampal de novo protein synthesis and actin rearrangement in extinction of contextual fear. J. Neurosci. 24: $1962-1966$.

Flood, J.F., Rosenzweig, M.R., Bennett, E.L., and Orme, A.E. 1973. The influence of duration of protein synthesis inhibition on memory. Physiol. Behav. 10: 555-562.

Frankland, P.W. and Bontempi, B. 2005. The organization of recent and remote memories. Nat. Rev. Neurosci. 6: 119-130.

Frankland, P.W., O'Brien, C., Ohno, M., Kirkwood, A., and Silva, A.J. 2001. $\alpha$-CaMKII-dependent plasticity in the cortex is required for permanent memory. Nature 411: 309-313.

Frankland, P.W., Bontempi, B., Talton, L.E., Kaczmarek, L., and Silva, A.J. 2004. The involvement of the anterior cingulate cortex in remote contextual fear memory. Science 304: 881-883.

Hall, J., Thomas, K.L., and Everitt, B.J. 2001. Cellular imaging of zif268 expression in the hippocampus and amygdala during contextual and cued fear memory retrieval: Selective activation of hippocampal CA1 neurons during the recall of contextual memories. J. Neurosci. 21: 2186-2193.

Keller, M., Meurisse, M., and Levy, F. 2005. Mapping of brain networks involved in consolidation of lamb recognition memory. Neuroscience 133: 359-369.

Kida, S., Josselyn, S.A., de Ortiz, S.P., Kogan, J.H., Chevere, I., Masushige, S., and Silva, A.J. 2002. CREB required for the stability of new and reactivated fear memories. Nat. Neurosci. 5: 348-355.

Kraus, M., Schicknick, H., Wetzel, W., Ohl, F., Staak, S., and Tischmeyer, W. 2002. Memory consolidation for the discrimination of frequency-modulated tones in mongolian gerbils is sensitive to protein-synthesis inhibitors applied to the auditory cortex. Learn. Mem. 9: 293-303.

Lattal, K.M. and Abel, T. 2004. Behavioral impairments caused by injections of the protein synthesis inhibitor anisomycin after contextual retrieval reverse with time. Proc. Natl. Acad. Sci. 101: $4667-4672$.

Lee, J.L., Everitt, B.J., and Thomas, K.L. 2004. Independent cellular processes for hippocampal memory consolidation and reconsolidation. Science 304: 839-843.

McBride, S.M., Giuliani, G., Choi, C., Krause, P., Correale, D., Watson, K., Baker, G., and Siwicki, K.K. 1999. Mushroom body ablation impairs short-term memory and long-term memory of courtship conditioning in Drosophila melanogaster. Neuron 24: 967-977.

McClelland, J.L., McNaughton, B.L., and O'Reilly, R.C. 1995. Why there are complementary learning systems in the hippocampus and neocortex: Insights from the successes and failures of connectionist models of learning and memory. Psychol. Rev. 102: 419-457.

Menzel, R. 2001. Searching for the memory trace in a mini-brain, the honeybee. Learn. Mem. 8: 53-62.

Merlo, E., Freudenthal, R., Maldonado, H., and Romano, A. 2005. Activation of the transcription factor NF- $\mathrm{B}$ by retrieval is required for long-term memory reconsolidation. Learn. Mem. 12: 23-29.

Milekic, M.H. and Alberini, C.M. 2002. Temporally graded requirement for protein synthesis following memory reactivation. Neuron 36: $521-525$.

Nadel, L. and Moscovitch, M. 1997. Memory consolidation, retrograde amnesia and the hippocampal complex. Curr. Opin. Neurobiol. 7: 217-227.

Nader, K. 2003. Memory traces unbound. Trends Neurosci. 26: 65-72.

Paxinos, G. and Franklin, K.B.J. 2000. The mouse brain in stereotaxic coordinates. Academic Press, San Diego, CA.

Pedreira, M.E. and Maldonado, H. 2003. Protein synthesis subserves reconsolidation or extinction depending on reminder duration. Neuron 38: 863-869.

Pedreira, M.E., Perez-Cuesta, L.M., and Maldonado, H. 2004. Mismatch between what is expected and what actually occurs triggers memory reconsolidation or extinction. Learn. Mem. 11: 579-585.

Rosenblum, K., Meiri, N., and Dudai, Y. 1993. Taste memory: The role of protein synthesis in gustatory cortex. Behav. Neural Biol. 59: $49-56$.

Shadmehr, R. and Holcomb, H.H. 1997. Neural correlates of motor memory consolidation. Science 277: 821-825.

Shimizu, E., Tang, Y.P., Rampon, C., and Tsien, J.Z. 2000. NMDA receptor-dependent synaptic reinforcement as a crucial process for memory consolidation. Science 290: 1170-1174.

Squire, L.R. and Alvarez, P. 1995. Retrograde amnesia and memory consolidation: A neurobiological perspective. Curr. Opin. Neurobiol. 5: $169-177$.

Squire, L.R., Stark, C.E., and Clark, R.E. 2004. The medial temporal lobe*. Annu. Rev. Neurosci. 27: 279-306.

Stickgold, R. and Walker, M.P. 2005. Memory consolidation and reconsolidation: What is the role of sleep? Trends Neurosci. 28: $408-415$.

Suzuki, A., Josselyn, S.A., Frankland, P.W., Masushige, S., Silva, A.J., and Kida, S. 2004. Memory reconsolidation and extinction have distinct temporal and biochemical signatures. J. Neurosci. 24: 4787-4795.

Tronel, S. and Sara, S.J. 2002. Mapping of olfactory memory circuits: Region-specific c-fos activation after odor-reward associative learning or after its retrieval. Learn. Mem. 9: 105-111.

Vianna, M.R., Szapiro, G., McGaugh, J.L., Medina, J.H., and Izquierdo, I. 2001. Retrieval of memory for fear-motivated training initiates extinction requiring protein synthesis in the rat hippocampus. Proc. Natl. Acad. Sci. 98: 12251-12254.

von Hertzen, L.S. and Giese, K.P. 2005. Memory reconsolidation engages only a subset of immediate-early genes induced during consolidation. J. Neurosci. 25: 1935-1942.

Wiltgen, B.J., Brown, R.A., Talton, L.E., and Silva, A.J. 2004. New circuits for old memories: The role of the neocortex in consolidation. Neuron 44: $101-108$.

Received December 30, 2005; accepted in revised form May 8, 2006. 


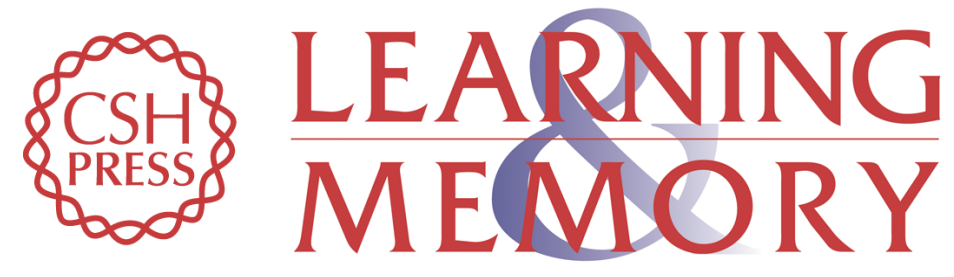

\section{Stability of recent and remote contextual fear memory}

Paul W. Frankland, Hoi-Ki Ding, Eiki Takahashi, et al.

Learn. Mem. 2006, 13:

Access the most recent version at doi:10.1101/lm.183406

References This article cites 42 articles, 18 of which can be accessed free at: http://learnmem.cshlp.org/content/13/4/451.full.html\#ref-list-1

License

Email Alerting Receive free email alerts when new articles cite this article - sign up in the box at the Service top right corner of the article or click here. 